\title{
A Holistic Review of Cement Composites Reinforced with Graphene Oxide
}

\author{
Yidong Xua ${ }^{\mathrm{a}}$, Juqing Zeng ${ }^{\mathrm{a}, \mathrm{b}}$, Wei Chen ${ }^{\mathrm{a}}$, Ruoyu Jin ${ }^{\mathrm{c}, *}$, Bo Li ${ }^{\mathrm{d}, \mathrm{e}, *}$, Zhihong Pan \\ a Ningbo Institute of Technology, Zhejiang University, Ningbo 315100, China; \\ b School of Civil Engineering and Architecture, Jiangsu University of Science and Technology, Zhenjiang \\ 212003, China; \\ c School of Environment and Technology, University of Brighton, Cockcroft Building 616, Lewes Road, \\ Brighton, U.K., BN2 4GJ \\ ${ }^{d}$ Department of Civil Engineering, University of Nottingham Ningbo China, Ningbo, 315100, China. \\ e Ningbo Nottingham New Materials Institute, University of Nottingham Ningbo China, Ningbo, China \\ *Corresponding authors: R.Jin@ brighton.ac.uk; bo.li@ nottingham.edu.cn
}

\begin{abstract}
Adopting a holistic review approach, this study started from the scientometric analysis by analyzing the mainstream journals, keywords, scholars, publications, and institutions active in the research of cement composites reinforced with graphene oxide (GO). Further statistical summary of research themes and in-depth discussion addressed the current research findings and gaps in terms of workability, mechanical properties, durability, and other issues when adding GO into cementitious materials. Recommendations for future research were provided, including but not limited to the necessity to study the long-term mechanical properties of cement composites reinforced with GO, and the application of GO in concrete.
\end{abstract}

Keywords: Scientometric analysis; Science mapping; cement composites; Graphene oxide; mechanical properties; durability

\section{Introduction}

The properties of cement pastes are believed to have the most important influence on the cement-based composites (e.g., concrete) [1], As the cement hydration products, crystal shapes and numbers, if controlled properly, could lead to great improvements in properties of cement pastes [2]. Graphene oxide (GO) is a graphene derivative, consisting of several layers of wrinkled two-dimensional carbon sheet with various oxygen-containing functional groups 
such as hydroxyl, carboxyl, and epoxy groups on its surface or between the inter-sheet layers [3] GO has been adopted by researchers [1,4-6] in controlling the formation of crystals in the cement hydration process. To improve the mechanical properties of concrete, adding fiber reinforced polymer (FRP) has been a widely adopted approach $[7,8]$. GO, as a promising option of a nano-reinforcement in cement composites, $[9,10]$ has been studied as a complement to FRP [11]. For example, GO was added in cementitious adhesive to enhance the bonding between NSM FRP and concrete substrate [7]. As a novel class of twodimensional nanoscale material [12], GO has attracted attention due to its high specific surface area, dispersibility in water, high aspect ratio and superior mechanical performance $[13,15]$. Another advantage of using GO is its lower cost by being synthesized in large quantities from inexpensive nature graphite flakes [9]. GO has been studied in the form of $\underline{\text { nanosheets, }}[9,12,16]$ which could be compounded by Hummer's method.[16] GO nanosheets provides a new method and direction towards the cement modification [16]. More research $[4,17-21]$ in GO-reinforced cementitious composites have been found in recent years.

Although it remains a relatively new research area in cement composites, the booming trend can be expected. There has been so far limited investigation on the current research status of applying GO in cementitious composites, specifically: 1) what have been the main research themes (e.g., mechanical properties); 2) what are the current research gaps (e.g., understanding of the mechanism of how GO affects the cement hydration); 3) what should be studied in the future for applying GO in cementitious composites. More research related to GO-reinforced cement composites remain to be performed, such as properties of composites containing recycled aggregates and GO as recommended by Long et al.[22]. There is a need for a holistic review to shed light on the state-of-the-art research on GO-reinforced cementitious composites. Adopting a comprehensive review approach consisting of a scientometric analysis with science mapping technology followed by the in-depth discussion, 
this study aims to achieve these following objectives: 1) to identify the influential publication sources, frequently studied themes (i.e., keywords), productive scholars and institutions, as well as literature with highest impacts in the field of GO-reinforced cement composites; 2) to analyze the ongoing mainstream research focuses (e.g., microstructure); 3) to address the current research gaps and to provide recommendations for the near-future research in cement composites reinforced with GO. This review-based study provides the long-term direction of how the emerging GO can be applied in material and structural engineering to meet the modern construction needs.

\section{Methodology}

This review-based study incorporated a scientometric review [23-25] and follow-up indepth discussion of the ongoing research themes in GO-reinforced cementitious materials. The rationale of adopting scientometric review is that multiple previous review-based studies in the fields of construction engineering, management, and materials [26] may be relying on subjective judgements which might be unreliable [27]. The scientometric analysis is able to prevent this subjectivity and tends to be more unbiased [28]. In this study, the scientometric review started from keyword search in Scopus, which was defined by AghaeiChadegani et al. [29] as the database with a wider coverage of journals and more recent publications compared to other search engines (e.g., Web of Science). Scopus has also been recommended by other studies [30,31] as the search engine of literature. The keyword search in Scopus was set as denoted below:

TITLE-ABS-KEY ("graphene oxide" AND (cement OR "cement paste" OR "cement composites" OR "cementitious materials"))

\section{The keywords input in the search included different types of construction materials with} cement in the mix design, such as mortar and concrete. The type of documents in the search was set limited to journals, excluding conference proceedings. Conference papers have been 
published in a larger number but with limited contribution to literature review considering the extra amount of complexity added to analyze them [32]. After these key journal articles were downloaded from Scopus, their abstracts were read by the research team members in this study to ensure that all articles fall into the research of cement composites reinforced by GO.

Science mapping was involved in the scientometric analysis. It describes and evaluates research policy purposes and process immense reservoirs of bibiometric data [33]. Science mapping also displays the structural and dynamic aspects of a scientific research [34], and represents spatially how disciplines, fields, and individual publications or authors related to one another [35]. The text-mining tool, VOSViewer [36], was adopted to assist the science mapping. Following the recommendations of Hosseini et al.[28]and Park and Nagy [37], VOSViewer was utilized to to achieve these objectives: 1) to import the literature sample downloaded from Scopus; 2) to identify the mainstream journal sources that publish research outputs of GO-reinforced cementitious materials; 3) to analyze research words that have been more widely studied; 4) to identify key researchers, articles, and institutions that contribute to the academic community. Clusters and inter-relatedness among keywords, researchers, articles, and institutions are also to be analyzed through science mapping. The information of influential studies, scholars, and keywords provides the big picture on the latest movement of academic research in a certain domain (e.g., GO-reinforced cement composites). It prevents researchers in the global academic community or those who are interested in the academic

\section{domain from being isolated.}

Following the scientometric analysis, a further in-depth discussion was performed to provide insights on the current research themes, gaps, and recommended future directions in GO-reinforced cementitious materials. The discussion divided the existing research into a few categories based on the scientometric analysis results. Existing findings and gaps within each category were described leading to future work. 


\section{Scientometric analysis}

Totally 113 relevant journal articles were selected following the literature search in Scopus using the methods described in Section 2. Compared to other research themes in cement composites, such as TITLE-ABS-KEY ("recycled aggregate" AND "cementitious materials") which resulted 611 relevant journal articles, the significantly smaller amount of articles found in Scopus indicates that GO-reinforced cementitious composites remain a relatively new research area. These articles are further analyzed according to the following subsections in terms of the overall literature sample, publication source, research keywords, productive and influential scholars, articles with highest impacts on the research community, and institutions active in GO-reinforced cementitious composites.

\subsection{Overall literature sample}

The overall literature sample is illustrated in Fig.1 according to the yearly publication from 2011 to 2018 .

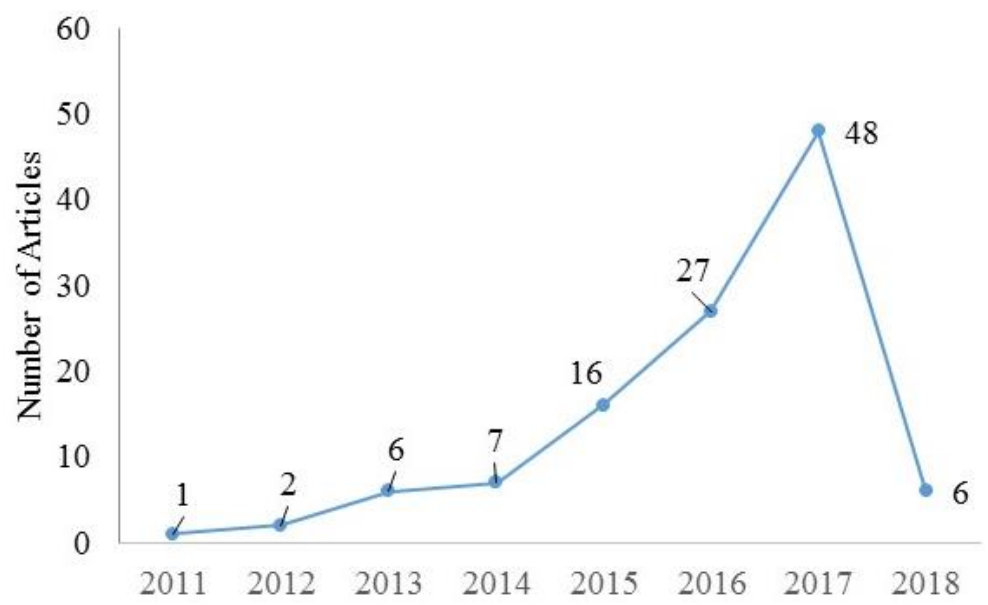

Note: the number of publication in 2018 is based on literature published up to 10 February 2018. Therefore, publications in 2018 are not completely counted.

Fig.1. Summary of publication years of journal articles focusing on graphene oxide applied in cement composite

The first relevant article was found in 2011, and few articles were found before 2014 Most studies were published after 2015 and increased significantly since then. The current number of publications in 2018 in incomplete (i.e., up to early February of 2018). But it can 
be expected that more literature will be published in the follow-up years.

\subsection{Analysis of publication sources}

Sources of these 113 articles were analyzed using Vosviewer as the science mapping visualization tool. Setting the minimum number of articles and minimum citations of a source to be 2 and 5 respectively in Vosviewer, totally 13 journals met the thresholds as visualized in Fig.2.

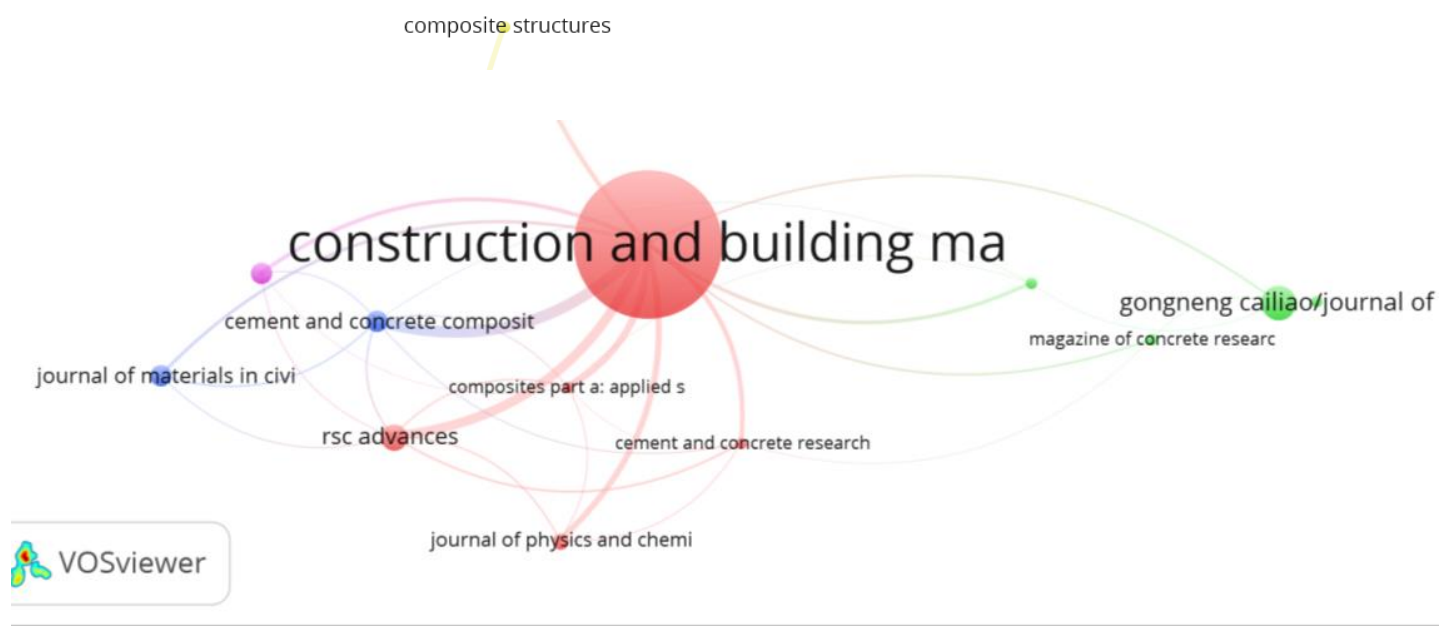

Note: The names of journals may not be completely displayed in VOSViewer. The full names of these journals can be found in Table 1.

Fig.2. Science mapping of sources of publications in GO-reinforced cement composites

The size of nodes and fonts in Fig. 2 indicate the impact of these journal sources. The thickness of the connection lines shows the inter-relatedness between two journals. For example, it can be found from Fig.2 that publications from Construction and Building Materials and Cement and Concrete Composites have been highly mutually cited. The colors of nodes in Fig. 2 show the clusters of journals which indicate that journals within the same cluster tend to be more inter-related based on their mutual citations. For example, Gongneng Cailiao/Journal of Functional Materials, Xinxing Tan Cailiao/New Carbon Materials, and Magazine of Concrete Research tended to form their own cluster with less connection to other journals visualized in Fig.2. Generally, it can be seen that Construction and Building Materials is the most influential journal in the research of GO-reinforced cement composites. 
It has also strong and wide connections with most other journals in this field. The more quantitative analysis of the influence of these journals is provided in Table 1.

Table 1.

Statistical analysis of journals in GO-reinforced cement composites

\begin{tabular}{|c|c|c|c|c|c|}
\hline Journal source & $\begin{array}{c}\text { Total } \\
\text { link } \\
\text { strength }\end{array}$ & $\begin{array}{c}\text { Number } \\
\text { of } \\
\text { journal } \\
\text { articles }\end{array}$ & Citations & $\begin{array}{c}\text { Avg. } \\
\text { pub. } \\
\text { Year }\end{array}$ & $\begin{array}{c}\text { Average } \\
\text { citations }\end{array}$ \\
\hline Carbon & 13 & 4 & 51 & 2017 & 12.8 \\
\hline $\begin{array}{c}\text { Cement and Concrete } \\
\text { Composites }\end{array}$ & 37 & 4 & 93 & 2016 & 23.3 \\
\hline $\begin{array}{c}\text { Cement and Concrete } \\
\text { Research }\end{array}$ & 19 & 2 & 32 & 2016 & 16.0 \\
\hline $\begin{array}{c}\text { Composite Structures } \\
\text { Composites Part A: Applied } \\
\text { Science And Manufacturing }\end{array}$ & 24 & 2 & 5 & 2017 & 2.5 \\
\hline $\begin{array}{c}\text { Construction and Building } \\
\text { Materials }\end{array}$ & 117 & 34 & 361 & 2016 & 10.6 \\
\hline $\begin{array}{c}\text { Fuhe Cailiao Xuebao/Acta } \\
\text { Materiae Compositae Sinica }\end{array}$ & 1 & 2 & 8 & 2015 & 4.0 \\
\hline $\begin{array}{c}\text { Gongneng Cailiao/Journal Of } \\
\text { Functional Materials }\end{array}$ & 7 & 7 & 18 & 2015 & 2.6 \\
\hline $\begin{array}{c}\text { Journal of Materials in Civil } \\
\text { Engineering }\end{array}$ & 11 & 4 & 46 & 2016 & 11.5 \\
\hline $\begin{array}{c}\text { Journal of Physics And } \\
\text { Chemistry of Solids }\end{array}$ & 19 & 3 & 29 & 2016 & 9.7 \\
\hline $\begin{array}{c}\text { Magazine of Concrete } \\
\text { Research }\end{array}$ & 6 & 2 & 15 & 2014 & 7.5 \\
\hline RSC Advances & 37 & 5 & 61 & 2016 & 12.2 \\
\hline $\begin{array}{c}\text { Xinxing Tan Cailiao/New } \\
\text { Carbon Materials }\end{array}$ & 10 & 2 & 2016 & 9.5 \\
\hline Note: Avg. Pub. Year stands & & & & & \\
\hline
\end{tabular}

Note: Avg. Pub. Year stands for the average year that the given item (e.g., Journal) publishes the research theme of graphene oxide in cement composites. The same abbreviation applies to the follow-up tables in this paper.

The impacts of a given journal are measured by their total link strength to other peer journals in Table 1, number of articles published, total citations received, and average citation per article. The average publication year is also listed in Table 1 to show the recentness of articles in the journal. Consistent to the visualization displayed in Fig.1, Construction and Building Materials ranks in the top in terms of the total link strength, number of publications, and total citations. It should be noticed that the average citation may vary from other measurements. It can be told that journals with highest citation per article related to GO- 
reinforced cement composites are: Cement and Concrete Composites, Cement and Concrete Research, Carbon, RSC Advances, and Journal of Materials in Civil Engineering. It is inferred that though with fewer articles published compared to Construction and Building Materials, these journals have made significant contributions to the research community in publishing research findings in GO-reinforced cement composites.

\subsection{Keyword analysis}

Keywords represent the core contents of existing studies and depict the research areas within a certain domain [38]. From totally 232 keywords extracted through Scopus database, the researchers set the minimum number of occurrences at 3 using Author Keyword. By removing generic keywords including graphene, graphene oxide, cement, cement paste, cement composites, cementitious materials, and further combining keywords with the same semantic meanings (e.g., strength, mechanical properties, and mechanical strength), totally 13 keywords were identified. Fig.3 displays these major keywords and their inter-relatedness.

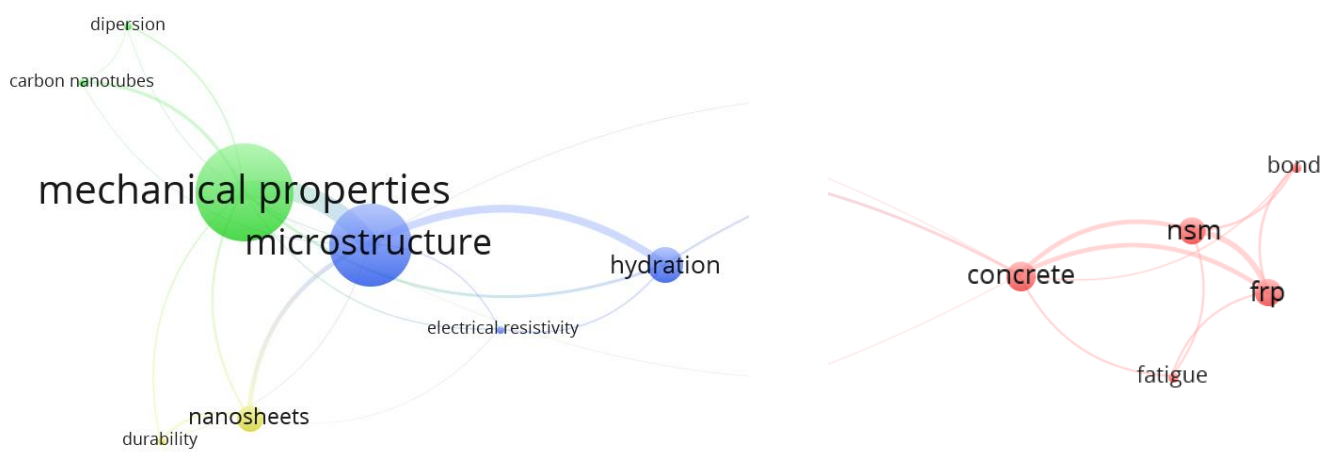

Note: NSM stands for near-surface mounted

Fig.3. Co-occurrence of keywords

It can be found in Fig.3 that mechanical properties and microstructure have been the two main research focuses. The connection line shows that microstructure study is highly related to the hydration of cement, including the early-age hydration $[39,40]$. The co-occurrences between microstructure and hydration can be found in numerous studies [1,41-42]. In comparison, durability has not been sufficiently studied. The existing studies $[15,44,45]$ of 
durability have more been based on GO in the form of nanosheets. Studies $[46,47]$ of mechanical properties were more closely co-occurring with dispersion and the form of GO in carbon nanotubes. Dispersion problem of GO nanosheets in alkaline cement matrix is another issue that restricts the further application of GO [49]. The cluster analysis also shows that these keywords (i.e., concrete, fatigue, NSM or near-surface mounted, bond, and FRP) [5053]tended to form their own inter-related network with weaker connections to the remaining keywords. The more quantitative measurements of keywords are provided in Table 2.

Table 2.

Statistical summaries of keywords studied in cement composites reinforced by GO

\begin{tabular}{|c|c|c|c|c|}
\hline Keywords & $\begin{array}{c}\text { Total link } \\
\text { strength }\end{array}$ & Occurrences & $\begin{array}{c}\text { Avg. Pub. } \\
\text { Year* }\end{array}$ & $\begin{array}{c}\text { Average } \\
\text { citations }\end{array}$ \\
\hline Bond & 3 & 3 & 2017 & 1.7 \\
\hline Carbon Nanotubes & 3 & 3 & 2017 & 5.0 \\
\hline Concrete & 8 & 8 & 2017 & 2.5 \\
\hline Dispersion & 2 & 3 & 2017 & 6.7 \\
\hline Durability & 3 & 3 & 2016 & 4.7 \\
\hline Electrical Resistivity & 3 & 3 & 2017 & 5.0 \\
\hline Fatigue & 3 & 3 & 2017 & 0.7 \\
\hline FRP & 7 & 7 & 2017 & 1.4 \\
\hline Hydration & 9 & 12 & 2015 & 13.3 \\
\hline Mechanical Properties & 20 & 33 & 2016 & 7.1 \\
\hline Microstructure & 22 & 28 & 2016 & 10.6 \\
\hline Nanosheets & 6 & 9 & 2016 & 4.6 \\
\hline NSM & 7 & 7 & 2017 & 1.4 \\
\hline
\end{tabular}

Consistent to the visualization in Fig.3, mechanical properties and microstructure top Table 2 by their total ink strength and occurrences. However, it is also noticed that cement hydration is the keyword that have received the most attention in the research of composites reinforced by GO, followed by microstructure, which is highly related to the study of hydration. Hydration is also the research topic that has been published earlier, with the average publication year in 2015, compared to other newly emerging keywords which are mostly published around 2017 (e.g., concrete and dispersion).

\subsection{Authorship analysis}


Awareness of existing scientific collaboration networks in a research field enhances the access to specialties and expertise, improves productivities, and prevent scholars' isolation within the academic community [28]. Science mapping was applied to study the most productive researchers and the collaboration among them. Among the totally 335 authors identified in VOSViewer, the researchers further set the minimum number of publications and the minimum number of citations of an author to be 3 and 30 respectively. A total of 21 authors met the thresholds. Among them, the most productive authors are visualized in Fig 4.

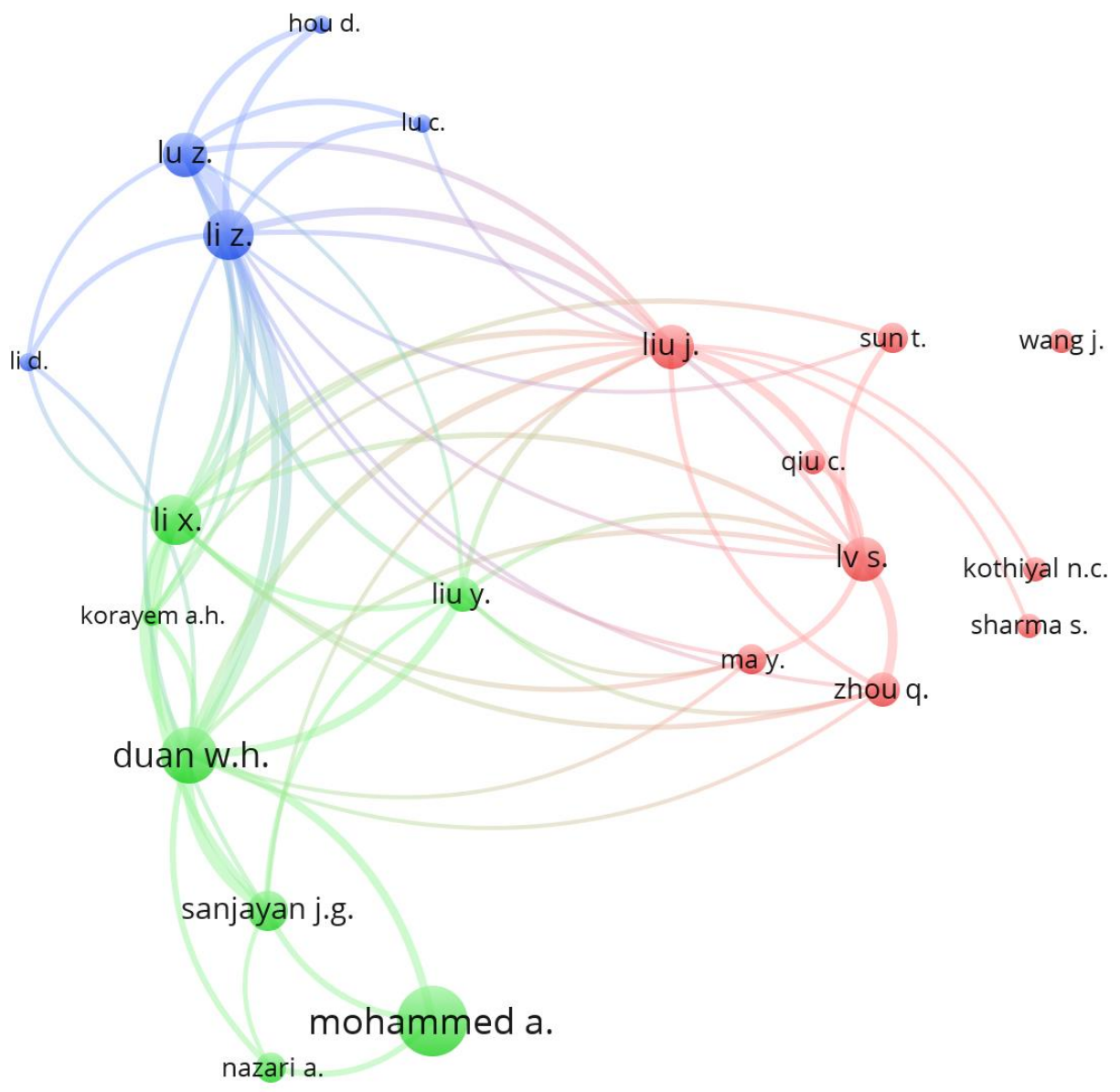

Fig.4. Productive scholars in the research of GO-reinforced cementitious composites

The collaboration network can be found from the clusters and connections lines shown in Fig.4. These most productive scholars (e.g., Duan W.H., Mohammed A., and Lv S.) all have established their research collaboration network. Strong collaborations among researchers can 
be found through science mapping. For example, Lu Z. and Li Z have co-authored in multiple publications $[42,54-56]$. Lv S. has been leading the research within the cluster in multiple research outputs $[4-6,15,41,44-45,57-59]$. Quantitative measurements provided in Table 3 offer more insights on the impact of these scholars.

Table 3.

Quantitative analysis of scholars active in the research of GO-reinforced cementitious composites

\begin{tabular}{|c|c|c|c|c|c|}
\hline Author & $\begin{array}{c}\text { Total link } \\
\text { strength }\end{array}$ & Publications & Citations & $\begin{array}{c}\text { Avg. pub. } \\
\text { Year }\end{array}$ & $\begin{array}{c}\text { Average } \\
\text { citation }\end{array}$ \\
\hline Duan W.H. & 202 & 10 & 174 & 2016 & 17.4 \\
\hline Hou D. & 65 & 3 & 54 & 2016 & 18.0 \\
\hline Korayem A.H. & 83 & 3 & 123 & 2015 & 41.0 \\
\hline Kothiyal N.C. & 50 & 4 & 35 & 2016 & 8.8 \\
\hline Li D. & 64 & 3 & 107 & 2016 & 35.7 \\
\hline Li X. & 163 & 9 & 96 & 2017 & 10.7 \\
\hline $\mathrm{Li}$ Z. & 180 & 9 & 90 & 2016 & 10.0 \\
\hline Liu J. & 155 & 8 & 168 & 2015 & 21.0 \\
\hline Liu Y. & 125 & 6 & 138 & 2016 & 23.0 \\
\hline Lu C. & 69 & 3 & 43 & 2015 & 14.3 \\
\hline Lu Z. & 151 & 8 & 85 & 2016 & 10.6 \\
\hline Lv S. & 145 & 8 & 155 & 2015 & 19.4 \\
\hline Ma Y. & 98 & 5 & 142 & 2014 & 28.4 \\
\hline Mohammed A. & 84 & 13 & 44 & 2017 & 3.4 \\
\hline Nazari A. & 58 & 5 & 33 & 2016 & 6.6 \\
\hline Qiu C. & 68 & 4 & 111 & 2014 & 27.8 \\
\hline Sanjayan J.G. & 122 & 7 & 54 & 2017 & 7.7 \\
\hline Sharma S. & 50 & 4 & 35 & 2016 & 8.8 \\
\hline Sun T. & 92 & 5 & 131 & 2014 & 26.2 \\
\hline Wang J. & 39 & 4 & 58 & 2016 & 14.5 \\
\hline Zhou Q. & 115 & 6 & 155 & 2014 & 25.8 \\
\hline
\end{tabular}

According to Table 3, most productive scholars measured by total link strength, number of publications, and total citations include Duan W.H., Li Z., Liu J., Lu Z., Lv S., Sanjayan J.G., and Zhou Q. The average citation per publication differs from other measurement items in Table 3. Korayem A.H. and Li D., although with only three journal articles published, top the average citation among all scholars, indicating the significance of their research in reinforcing cement composites with GO. Other scholars with significant contribution to the research community include Ma Y., Qiu C., Sun T., Zhou Q., and Liu Y., most of whom fall 
into the cluster of Lv S shown in Fig.4. The average publication year indicates that scholars that have been active and productive with more recent publications, including Li X., Mohammed A., and Sanjayan J.G.

\subsection{Citation of articles}

Journal articles that have received the highest citations were summarized. Setting the minimum number of citations of a journal article at 20, totally 19 out of 113 articles were extracted. Among them articles received highest citations are visualized in Fig.5.

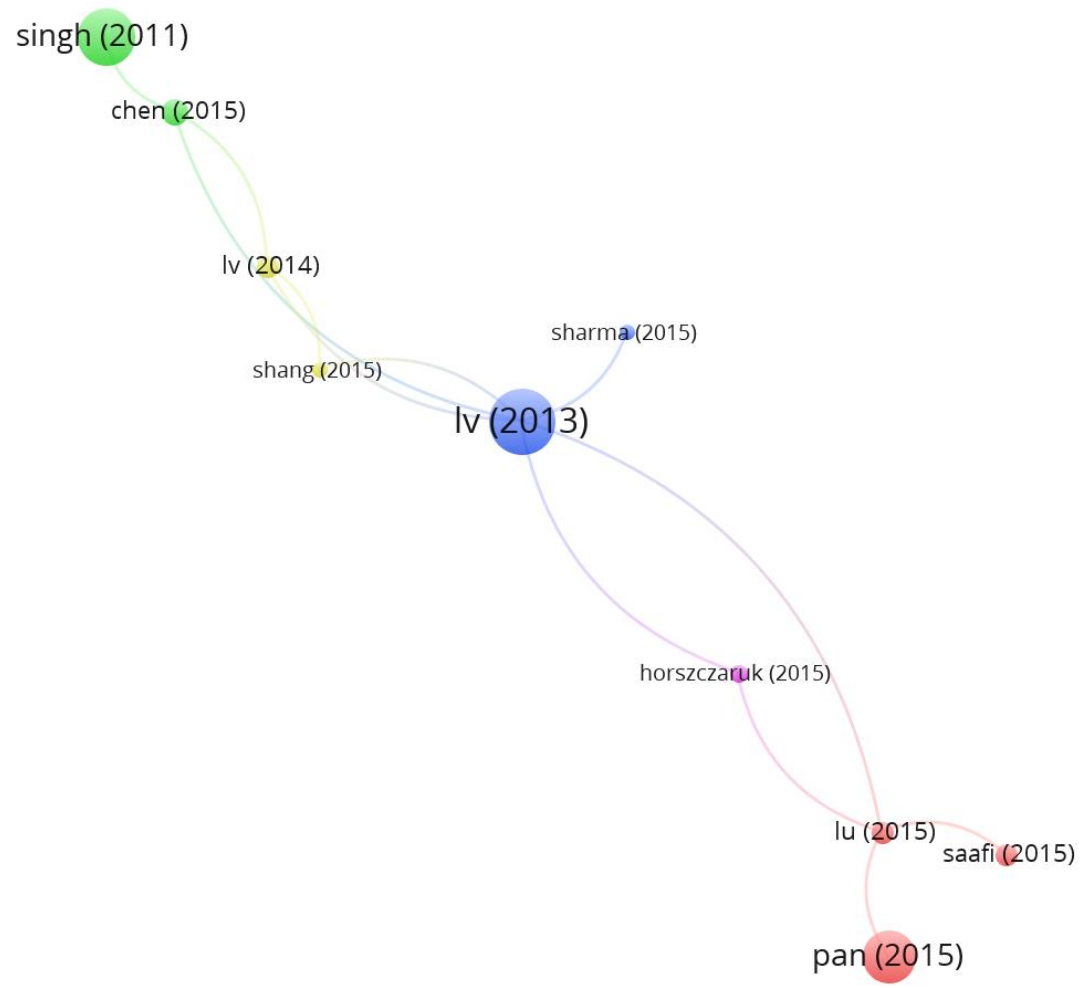

Note: Only the first author of each selected article is displayed in VOSviewer.

Fig.5. Mapping of most influential articles in GO used in cement composites

The connection lines in Fig.5 identify the inter-relatedness of articles. The number of citations of these most influential articles are listed in Table 4.

Table 4.

Articles that have received highest citations by February 2018 


\begin{tabular}{|c|c|c|}
\cline { 2 - 3 } & $\begin{array}{c}\text { Effect of graphene oxide on the rheological properties of cement } \\
\text { pastes [60] }\end{array}$ & 22 \\
\hline Chang et al. (2015) & $\begin{array}{c}\text { Graphene oxide-deposited carbon fiber/cement composites for } \\
\text { electromagnetic interference shielding application [11] }\end{array}$ & 36 \\
\hline $\begin{array}{c}\text { Horszczaruk et al. } \\
\text { (2015) }\end{array}$ & $\begin{array}{c}\text { Nanocomposite of cement/graphene oxide - Impact on hydration } \\
\text { kinetics and Young's modulus [61] }\end{array}$ & 24 \\
\hline Pan et al. (2015) & $\begin{array}{c}\text { Mechanical properties and microstructure of a graphene oxide- } \\
\text { cement composite [62] }\end{array}$ & 71 \\
\hline Lu et al. (2015) & $\begin{array}{c}\text { Mechanism of cement paste reinforced by graphene oxide/carbon } \\
\text { nanotubes composites with enhanced mechanical properties [47] }\end{array}$ & 30 \\
\hline Saafi et al. (2015) & $\begin{array}{c}\text { Enhanced properties of graphene/fly ash geopolymeric composite } \\
\text { cement [17] }\end{array}$ & 30 \\
\hline Sharma and Kothiyal \\
(2015) & $\begin{array}{c}\text { Influence of graphene oxide as dispersed phase in cement mortar } \\
\text { matrix in defining the crystal patterns of cement hydrates and its } \\
\text { effect on mechanical, microstructural and crystallization properties } \\
\text { [63] }\end{array}$ & 23 \\
\hline Lv et al. (2014) & $\begin{array}{c}\text { Effect of GO nanosheets on shapes of cement hydration crystals and } \\
\text { their formation process [1] }\end{array}$ & 31 \\
\hline Lv et al. (2013) & $\begin{array}{c}\text { Effect of graphene oxide nanosheets of microstructure and } \\
\text { mechanical properties of cement composites [59] }\end{array}$ & 89 \\
\hline Singh et al. (2011) & $\begin{array}{c}\text { Graphene oxide/ferrofluid/cement composites for electromagnetic } \\
\text { interference shielding application [64] }\end{array}$ & 76 \\
\hline
\end{tabular}

It can be found from Table 4 that articles with highest citations basically focus on the research of cement hydration, mechanical properties, micro-structure and related mechanism within GO-reinforced cement composites.

\subsection{Research institutions}

Institutions with high impacts on the research community of GO-reinforced cement composites were summarized. Setting minimum number of publications and minimum number of citations to be 2 and 10 respectively in VOSViewer, 10 out of 223 institutions were extracted as shown in Fig.6. 


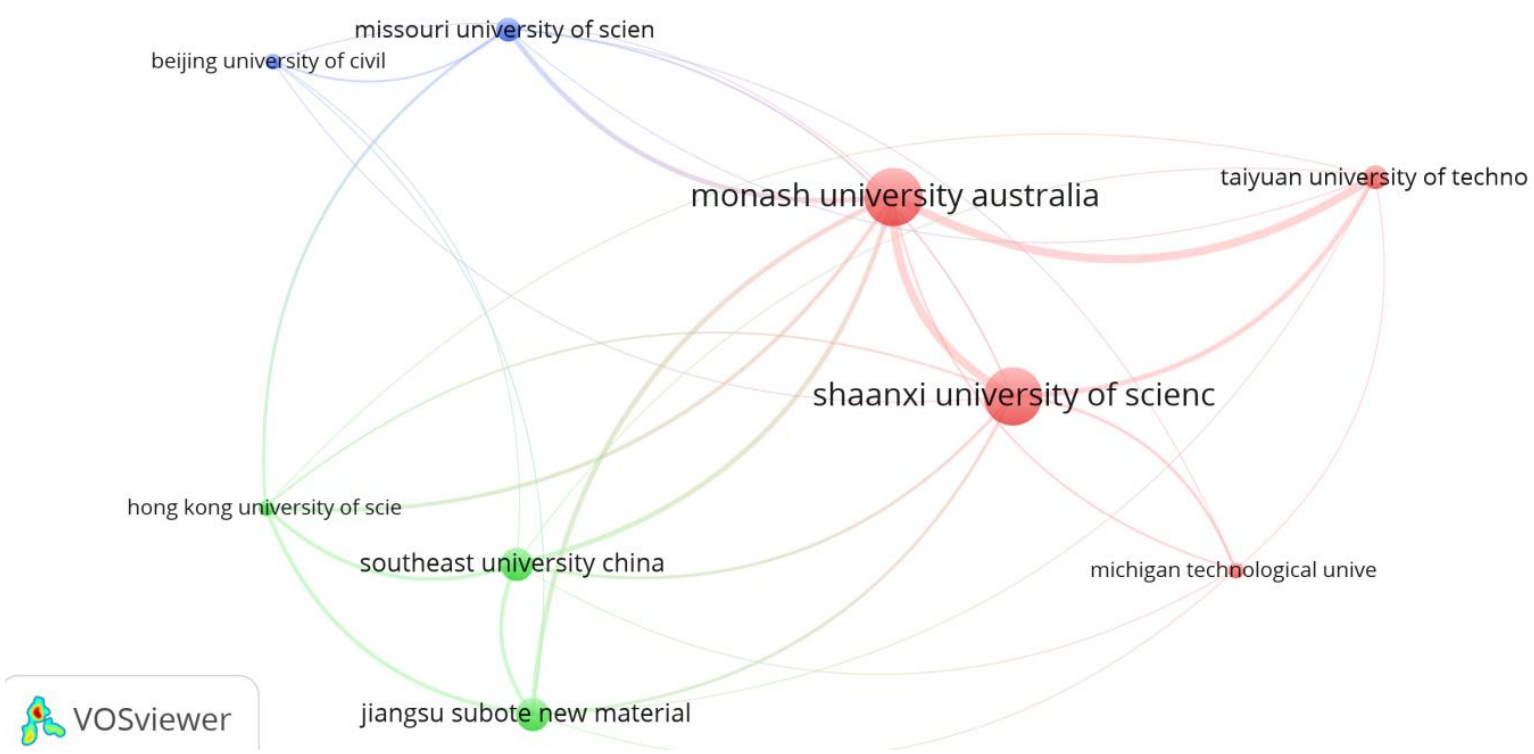

Note: The names of institutions may not be completely displayed in VOSViewer. The full names of these institutions can be found in Table 5 .

Fig.6. Science mapping of institutions active in the research of GO-reinforced cement composites

Three main clusters are identified in Fig.6. International collaboration among institutions can be found in each of the three clusters, for example, the collaboration between Hong Kong and mainland of China, between China and U.S., as well as among China, Australia, and U.S. According to the node size and thickness of collection lines, Monash University Australia and Shanxi University of Science and Technology China have been most productive in the research of GO-reinforced cement composites. Quantitative measurements of the research impacts of these institutions are provided in Table 5.

Table 5.

Measurements of research impacts of institutions in GO-reinforced cement composites

\begin{tabular}{|c|c|c|c|c|c|}
\hline Institution & $\begin{array}{c}\text { Total } \\
\text { link } \\
\text { strength }\end{array}$ & $\begin{array}{c}\text { Number } \\
\text { of } \\
\text { articles }\end{array}$ & $\begin{array}{c}\text { Total } \\
\text { Citations }\end{array}$ & $\begin{array}{c}\text { Avg. pub. } \\
\text { year }\end{array}$ & $\begin{array}{c}\text { Average } \\
\text { citation }\end{array}$ \\
\hline $\begin{array}{c}\text { Beijing University of Civil } \\
\text { Engineering and Architecture } \\
\text { China }\end{array}$ & 6 & 2 & 19 & 2016 & 9.5 \\
\hline $\begin{array}{c}\text { Hong Kong University of Science } \\
\text { and Technology }\end{array}$ & 18 & 2 & 43 & 2016 & 21.5 \\
\hline $\begin{array}{c}\text { Jiangsu Subote New Material Co., } \\
\text { Ltt. China }\end{array}$ & 19 & 4 & 22 & 2017 & 5.5 \\
\hline $\begin{array}{c}\text { Michigan Technological } \\
\text { University United States }\end{array}$ & 9 & 2 & 28 & 2016 & 14.0 \\
\hline $\begin{array}{c}\text { Missouri University of Science } \\
\text { and Technology United States }\end{array}$ & 14 & 3 & 24 & 2017 & 8.0 \\
\hline
\end{tabular}




\begin{tabular}{|c|c|c|c|c|c|}
\hline Monash University Australia & 40 & 7 & 129 & 2016 & 18.4 \\
\hline $\begin{array}{c}\text { Shaanxi University of Science } \\
\text { And Technology China }\end{array}$ & 28 & 7 & 170 & 2014 & 24.3 \\
\hline Southeast University China & 19 & 4 & 22 & 2017 & 5.5 \\
\hline $\begin{array}{c}\text { Taiyuan University of } \\
\text { Technology China }\end{array}$ & 19 & 3 & 21 & 2017 & 7.0 \\
\hline
\end{tabular}

Five out of the totally ten research-active institutions listed in Table 5 come from the mainland of China, the rest institutions are from U.S., Australia, and Hong Kong respectively. Consistent with the findings in Fig.6, Monash University Australia and Shanxi University of Science and Technology China top Table 5 based on their total link strength, number of publications, and total citations. Both universities are also among the institutions with highest average citation. Shanxi University of Science and Technology China is also the institution with longer history of established research profile in GO-reinforced cement composites. Other institutions have been more recently involved in the same research area, such as Missouri University of Science and Technology United States and Southeast University China.

\section{Discussion and findings}

Compared to other more widely studied area in construction materials (e.g., recycled aggregate concrete), the limited studies (i.e., 113 journal articles found in Scopus) of GO applications in cementitious materials indicate that GO reinforced cement composites is a relatively new research direction. The first journal article in GO reinforced cement composites was published in 2011 and few studies were found before 2014. Since 2015, these studies have been skyrocketing year by year, indicating the emerging research direction of adopting GO to reinforce cementitious materials, due to its extraordinary properties [54]. However, barriers that restrict GO's real-world application have not been well addressed, such as agglomeration [48]. GO have been studied in multiple forms and sizes, such as nanosheets [65], nanoplatelets [66], and aggregates [56]. Currently the research in cement 
composites reinforced by GO is still at the early stage. The main themes and future research directions can be summarized in terms of the cement composites' workability, the formation mechanism and performance control of hydration products' microstructure, mechanical properties of cement composites, durability, and volume stability.

\subsection{GO types and preparation}

GO exists in multiple forms, such as GO nanosheets [4] and GO nanotubes [67]. These commonly studied GO types and the method of their preparation are summarized in Table 6 .

Table 6.

Summary of literature on preparing various types of GO

\begin{tabular}{|l|l|c|}
\hline \multicolumn{1}{|c|}{ Type of GO } & \multicolumn{1}{|c|}{ Method of preparation } & Reference \\
\hline GO & In-situ reduced GO [17] \\
\hline $\begin{array}{l}\text { GO-encapsulated silica fume } \\
\text { GOSF) }\end{array}$ & $\begin{array}{l}\text { The combination of modified silica fume and GO by } \\
\text { electrostatic action to form suspension using magnetic } \\
\text { stirring }\end{array}$ & Shang [60] \\
\hline $\begin{array}{l}\text { Single-walled } \\
\text { nanotubes }\end{array}$ & $\begin{array}{l}\text { Adopting Hummers method, GO being composited with } \\
\text { single-walled carbon nanotubes }\end{array}$ & Li [67] \\
\hline $\begin{array}{l}\text { GO-deposited carbon fiber (GO- } \\
\text { FF) }\end{array}$ & $\begin{array}{l}\text { Using electrophoretic deposition and GO being prepared } \\
\text { adopting the Hummers method }\end{array}$ & Chen [11] \\
\hline $\begin{array}{l}\text { Polycarboxylate (PC) and GO } \\
\text { nanosheet composites ( GON- } \\
\text { PCS ) }\end{array}$ & $\begin{array}{l}\text { The copolymerization caused by GO nanosheet and the } \\
\text { monomers of polycarboxylic acid-based water-reducer }\end{array}$ & Lv [4] \\
\hline GO and Polyetheramine (GOM) & $\begin{array}{l}\text { Synthesis of chemically functionalized GO through the } \\
\text { reaction of Polyetheramine and GO }\end{array}$ & Wang [68] \\
\hline
\end{tabular}

\subsection{Cement composites'workability}

The fast movement and increasing applications of high-rise and long-span structures require a better concrete performance. Self-compacting concrete has been successfully applied in practice. Nevertheless, multiple studies $[55,62,69-71]$ indicated that GO would reduce the fluidity of the cement slurry and increase its viscosity, further affecting concrete workability. Wang et al.[69] found that cement slurry's fluid loss would reach $70 \%$, with its viscosity increased by $1,850 \%$ when cementitious materials were added with $0.05 \%$ GO by weight. GO is a two-dimensional carbon allotrope [12] and GO sheets tend to be hydrophilic [72]. Therefore, GO increased cement pastes' viscosity due to its two-dimensional planar honeycomb lattice [73] microstructure, high specific surface area, and hydrophilic feature 
$[5,6,74]$. Although there have been studies $[68,75]$ attempting to improve the rheological properties of cement-based composites, the problem of slump loss has not been completely solved. Coarse aggregate in ready-mix concrete would further increase the internal friction resistance, causing difficulties in construction. Further research is needed to explore the feasibility of adopting the modern molecular cutting and grafting technology and applying GO in multi-functional chemical admixture in improving concrete workability and reducing slump loss. There is a large potential for applying GO-reinforced cementitious composites (e.g., concrete). More research is needed in improving the workability of concrete containing $\mathrm{GO}_{2}$ for example, applying the self-assembly or morphological technologies [88] to incorporate GO in chemical admixture to improve concrete workability.

\section{4.‥ Formation mechanism of cement hydration products}

Hydration products determine the performance of cement-based composites. Research [1,4-6] has shown that GO has a significant effect in the cement hydration products. Lv et al. [5] observed that at the existence of GO, the hydration products tended to be well-ordered crystalline or petal-like shapes as shown in Fig.7.

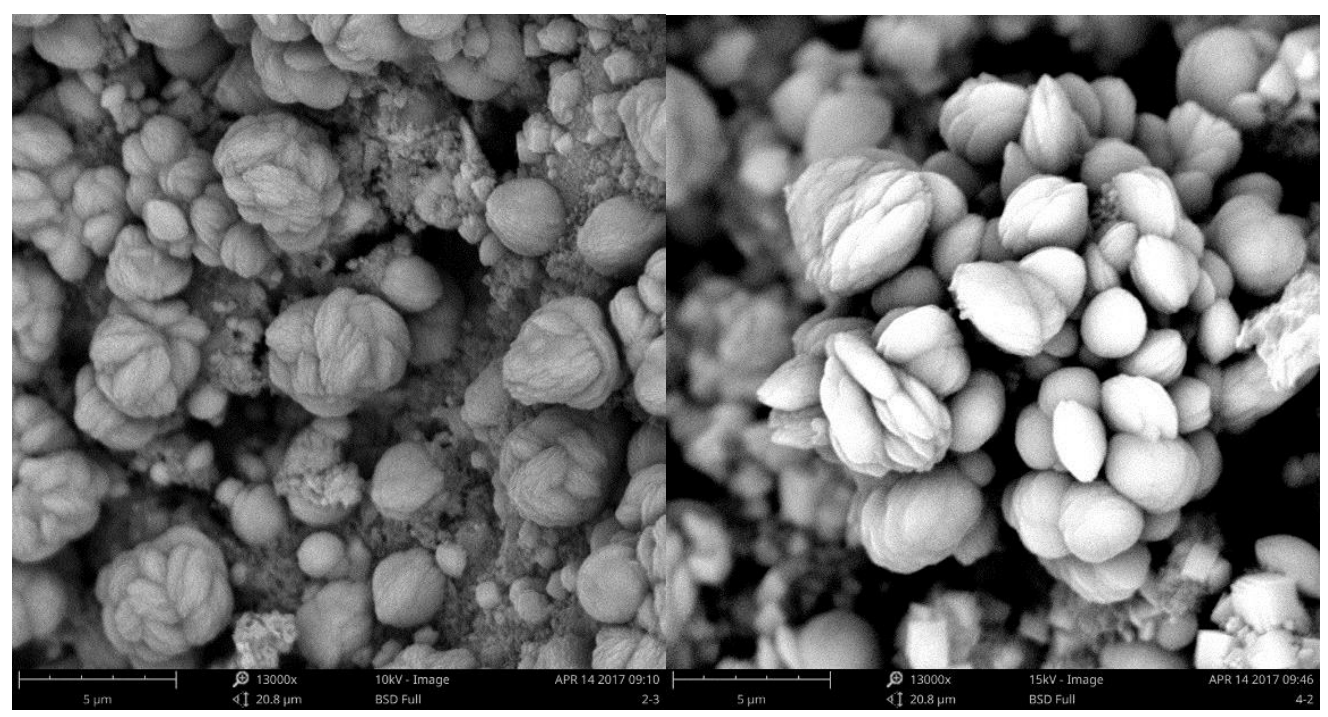

Fig.7. Cement hydration products in crystalline or petal-like shapes

The pores were more uniform and smaller as GO had the sheet layers with higher strength and toughness, and hence enhancing the growth of cement hydration products. Jiang 
and Wang [77] and Wang et al.[69] supported the finding of Lv et al.[5].However, the research of Horszczaruk et al.[61] showed that the addition of GO did not cause significant differences in the formation and shapes of hydration products. Cui et al.[78] further disagreed with Lv et al.[5]that the crystalline or petal-shaped substances were not part of hydration products, but just calcium carbonate due to the carbonation reaction when preparing the sample of cement composites. The understanding of the formation mechanism and shapes of hydration products were further explored by Lv et al.[44,57] focusing on controlling the shapes of hydration products by doping GO nanosheets. The formation mechanism of cement hydration products involving GO_is illustrated in Fig. 8 .

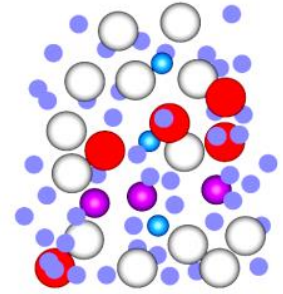

(a) Hydration reaction

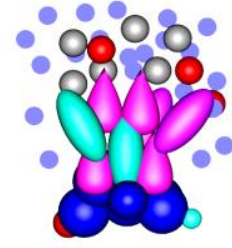

(b) Assembling

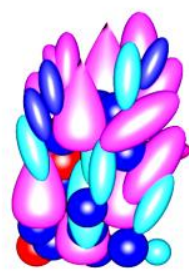

(c) Flower-like crystal

Formation mechanism in holes/cracks

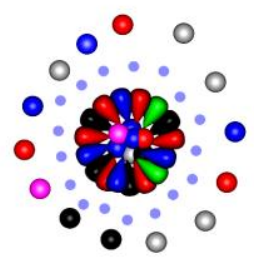

(d) Assembling

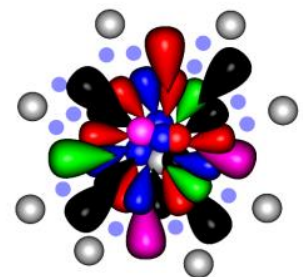

(e) Assembling

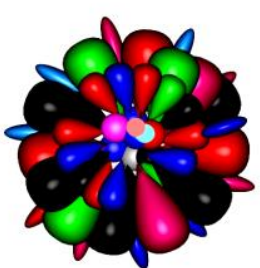

(f) Flower-like pattern

Formation mechanism in dense environment

Fig.8. The formation mechanism of hydration products in well-ordered crystalline or petal-like shapes (adapted from Lv et al.[44]).

Future research can target on altering the microstructure of cement composites reinforced by GO in order to achieve the desired performance of composite materials. Further research can also be performed to simulate the hydration process using molecular dynamics method 
adopted by Hou et al.[79] and Fan et al.[80], and to establish a microstructure model of hydration products.

\section{4.‥ Mechanical properties}

The mechanical properties of cement composites reinforced with GOs have been relatively more widely studied compared to other themes (e.g., durability). Unlike the formation mechanism of hydration products which have raised more arguments in the research community, existing studies [5,6,46,69,81-83] have generally agreed that GO improves the mechanical properties of cementitious composites. However, there are inconsistencies of the increase rate by adding GO. An analysis of these studies $[11,41,60,62]$ revealed a wide range of strength increase rate of GO-reinforced composites, from $15 \%$ to $160 \%$ in compressive strength increase, and $18 \%$ to $185 \%$ in split tensile strength increase. This wide range of strength increase rate could be partly explained by the mixture percentage differences of GO in cement composites (i.e., from $0.02 \%$ to $4 \%$ ) as well as the preparation of GO samples [84], such as GO sheets or single wall carbon nanotubes [67], graphene oxide encapsulated silica fume [60], and GO-deposited carbon fiber [10] ${ }^{[11]}$. Besides the dosage of GO additives, other factors such as surface chemistry, size, charge, and defects of graphene structures [85] could also affect the resulted mechanical performance of cement composites. The longer-term mechanical properties of cement composites reinforced with GO has not been sufficiently studied. The researchers are also concerned on the reduction of the longterm strength of cement composites due to the delayed formation of calcium alum under high temperature. The effects of high temperature in properties of concrete containing GO has raised research attention [86]. Few studies can be found so far addressing the issue of whether GO could prevent this long-term strength loss. The other concern is whether GO could enhance the resistance to material fatigue in cement composites, as material fatigue is a widely concerned issue. 


\section{4.․․ Durability}

Compared to the mechanical properties, durability of GO-reinforced cement composites have not been sufficiently studied. The durability issue of cementitious materials covers a wide scope, including reinforcement corrosion caused by chloride or carbonation, freezethaw cycle, and alkali aggregate reaction, etc. GO can be directly correlated with the corrosion resistance of gephene-reinforced concrete [87]. Mohammed et al.[14] found that GO could reduce the penetration depth of chloride ions. The reduced penetration depth could be explained by the inter-connected GO layers which form the sponge-shaped structure to capture chloride ions [14]. Tong et al.[87] found that the anti-freezing performance of GOreinforced mortar was worse than the standard mortar, possibly due to the absorption and desorption of nano-level pores within mortar. Lv et al.[44] revealed that GO-reinforced composites could reduce the permeability depth by $72 \%$, improve the dynamic modulus of elasticity by $78 \%$ after 100 freeze-thaw cycles, and decrease the 28 -day's carbonation depth by $66 \%$. The improved durability by adding GO nanosheets into cement composites was due to the orderly formed crystal-like hydration products which reduced the cracking and hazardous pores in the microstructure [44]. Despite of these few studies, there have been so far limited investigation in these common durability issues for GO-reinforced cement composites. Specifically, limited studies have focused on analyzing the mechanism and establishing the theoretical models within durability issues. More studies can be performed to address the GO performance in an alite or alkailine paste as it has been found by Ghazizadeh et al.[88] that GO would be reduced with its functional groups at a high $\mathrm{PH}$.

\section{4. . Other research themes}

The volume stability of cementitious composites affects the cracking sensitivity of concrete structure in terms of autogenous shrinkage, plastic shrinkage, drying shrinkage, and temperature deformation and creep. The mechanisms of these deformations, although 
varying, are related to the microstructural change within cement composites, change of hydration products' density, and viscous flow. Adding GO into cement composites would significantly affect the pore structure and hydration of cement composites, leading to the further effects on volume stability. Nevertheless, there have been few studies investigating the volume stability of GO-reinforced cement composites. It should also be noticed that most existing studies focused on applying GO into cement slurry or mortar, but with limited studies of GO applications in concrete. As concrete is the most widely used construction materials [89], more studies on GO applied in concrete should be conducted in the future. Future research directions in GO-reinforced concrete should be extended from the perspective of material properties to structural application, and ultimately leading to the application of GO-reinforced concrete in construction practice.

\section{Conclusions}

Aiming to investigate the current status of research in graphene oxide-reinforced cementitious composites and provide the corresponding research directions, this review-based study adopted a holistic approach incorporating both scientometric analysis and in-depth review of existing literature. The research in graphene oxide-reinforced cementitious composites is a relatively new yet emerging area in modern cementitious materials. The first publication in this area was found in 2011, and only 113 journal articles were found up to February 2018. The research in graphene oxide-reinforced cement composites has gained increasing popularity especially since 2015 . It is expected that more near-future studies will be published in this area. The scientometric analysis revealed that:

- Construction and Building Materials was the most influential journal in publishing studies related to graphene oxide-reinforced cement composites based on its total link strength, number of articles published, and citations;

- mechanical properties and microstructure were the most frequently studied keywords. 
Microstructure has been found with high inter-relatedness with cement hydration. In comparison, other areas have not been sufficiently researched, including durability, cement hydration, dispersion of GO, and material fatigue;

- most influential and productive scholars in the area of graphene oxide-reinforced cement composites were identified, including Duan W.H., Lv S., Mohammed A., Li X., Li Z., Liu, J., and Lu, Z. The research network led by Lv S. had significant contribution to the academic field, with multiple researchers receiving high citation rates per publication;

- journal articles receiving the highest citations and institutions active in the research of graphene oxide-reinforced cement composites were also identified to provide a macro picture of the scholarly community worldwide.

Further in-depth review of literature indicated that the formation of differently-shaped cement hydration products has not been well understood. There have been arguments among researchers regarding how graphene oxide would affect the cement hydration products. Multiple other themes remain to be explored, such as the microscopic mechanical properties of hydration products from cement composites reinforced with graphene oxide. More research has focused on the mechanical properties of graphene oxide-reinforced cement composites, but the durability issue remain under-studied. Recommendations for near-future research are provided below:

- effective method in improving the workability of cementitious materials when reinforced with graphene oxide;

- further studies of the formation mechanism of cement hydration products, and how to adapt the microstructure of graphene oxide-reinforced cement composites to achieve desired properties of composites;

- studies on the long-term mechanical properties of graphene oxide-reinforced cement composites; 
- durability evaluation of graphene oxide-reinforced cement composites based on different graphene oxide types (e.g., nanosheets, nanotubes, and graphene oxide with fiber, etc.);

- volume stability issue within graphene oxide-reinforced cement composites;

- experimental studies and applications of graphene oxide in concrete from both the material and structural perspectives.

\section{Acknowledgement}

The authors wish to acknowledge the financial support of National Natural Science Foundation of China (Grant No. 51778577), National Science and Technology Support Program of China (Grant No. 2015BAL02B03) and Ningbo the Benefit of People Program from the Ningbo Science and Technology Bureau (Contract No. 2015C50049).

\section{References}

[1] Lv S, Liu J, Sun T, Ma Y, Zhou Q. Effect of GO nanosheets on shapes of cement hydration crystals and their formation process. Constr Build Mater. 2014;64: 231-9.

[2] Shaikh, F.U.A. and S.W.M. Supit, Mechanical and durability properties of high volume fly ash (HVFA) concrete containing calcium carbonate $(\mathrm{CaCO} 3)$ nanoparticles. Constr Build Mater, 2014. 70: p. 309-321.

[3] Chen D, Feng H, Li J. Graphene Oxide: Preparation, Functionalization, and Electrochemical Applications. Chem Rev. 2012;112(11): 6027-53.

[4] Lv SH, Deng LJ, Yang WQ, Zhou QF, Cui YY. Fabrication of polycarboxylate/graphene oxide nanosheet composites by copolymerization for reinforcing and toughening cement composites. Cem. Concr. Compos. 2016;66: 1-9.

[5] Lv, S.H., et al., Study on reinforcing and toughening of graphene oxide to cement-based composites. Gongneng Cailiao/Journal of Functional Materials, 2013. 44(15): p. 2227-31.

[6] Lv, S.H., et al., Effects of graphene oxide on fluidity of cement paste and structure and properties of hardened cement paste. Gongneng Cailiao/Journal of Functional Materials, 2015. 46(4): p. 04051-04056.

[7] Al-Saadi NTK, Mohammed A, Al-Mahaidi R. Bond performance of NSM CFRP strips embedded in concrete using direct pull-out testing with cementitious adhesive made with graphene oxide. Constr Build Mater. 2018;162: 523-33.

[8] Zeyu Lu A AHBC, A ZL. Highly dispersed graphene oxide electrodeposited carbon fiber reinforced cement-based materials with enhanced mechanical properties. Cem. Concr. Compos. 2018: 220-8

[9] Zhao L, Guo X, Liu Y, Ge C, Chen Z, Guo L, et al. Investigation of dispersion behavior of GO modified by different water reducing agents in cement pore solution. Carbon. 2018;127: 255-69.

[10] Yang H, Monasterio M, Cui H, Han N. Experimental study of the effects of graphene oxide on microstructure and properties of cement paste composite. Composites Part A: Applied Science and Manufacturing. 2017;102: 263-72.

[11]Chen J, Zhao D, Ge H, Wang J. Graphene oxide-deposited carbon fiber/cement 
composites for electromagnetic interference shielding application. Constr Build Mater. 2015;84: 66-72.

[12] Chuah S, Li W, Chen SJ, Sanjayan JG, Duan WH. Investigation on dispersion of graphene oxide in cement composite using different surfactant treatments. Constr Build Mater. 2018;161: 519-27.

[13] Chen Z, Zhou X, Wang X, Guo P. Mechanical behavior of multilayer GO carbon-fiber cement composites. Constr Build Mater. 2018;159: 205-12.

[14] Mohammed A, Sanjayan JG, Duan WH, Nazari A. Incorporating graphene oxide in cement composites: A study of transport properties. Constr Build Mater. 2015;84: 341-7.

[15] Shenghua Lv STJL. Use of graphene oxide nanosheets to regulate the microstructure of hardened cement paste to increase its strength and toughness. Crystengcomm. 2014: 1636.

[16] Wang M, Wang R, Yao H, Farhan S, Zheng S, Du C. Study on the three dimensional mechanism of graphene oxide nanosheets modified cement. Constr Build Mater. 2016;126: 730-9.

[17] Mohamed Saafi A LTBJ. Enhanced properties of graphene/fly ash geopolymeric composite cement. Cement Concrete Res;67(2015): 292-9.

[18] Ranjbar N, Mehrali M, Mehrali M, Alengaram UJ, Jumaat MZ. Graphene nanoplateletfly ash based geopolymer composites. Cement Concrete Res. 2015;76: 222-31.

[19] Du H, Pang SD. Enhancement of barrier properties of cement mortar with graphene nanoplatelet. Cement Concrete Res. 2015;76: 10-9.

[20] Mohammed A, Sanjayan J, Nazari A, Al-Saadi NTK, Duan W. Graphene Oxide as Additive to Replace Using Air-Entraining Agents. ACI Mater J. 2017;114(6).

[21] Mohammed A, Al-Saadi NTK, And R. Al-Mahaidi MA. Utilization of Graphene Oxide to Synthesize High-Strength Cement-Based Adhesive. J Mater Civil Eng. 2017;94: 29.

[22] Long W, Wei J, Ma H, Xing F. Dynamic Mechanical Properties and Microstructure of Graphene Oxide Nanosheets Reinforced Cement Composites. Nanomaterials-Basel. 2017;7(12): 407.

[23]Şenel, E. and E. Demir, Bibliometric and Scientometric Analysis of the Articles Published in the Journal of Religion and Health Between 1975 and 2016. Journal of Religion and Health, 2018: p. 1-10.

[24]Glänzel, W. and L. Zhang, Scientometric research assessment in the developing world: A tribute to Michael J. Moravcsik from the perspective of the twenty-first century. Scientometrics, 2018: p. 1-16.

[25]Jacso, P., The scientometric portrait of Eugene Garfield through the free ResearcherID service from the Web of Science Core Collection of 67 million master records and 1.3 billion references. Scientometrics, 2018: p. 1-11.

[26]Ke, Y., et al., Research trend of public-private partnership in construction journals. Journal of Construction Engineering and Management, 2009. 135(10): p. 1076-1086.

[27] Song, J., H. Zhang, and W. Dong, A review of emerging trends in global PPP research: analysis and visualization. Scientometrics, 2016. 107(3): p. 1111-1147.

[28] Hosseini MR, Martek I, Zavadskas EK, Aibinu AA, Arashpour M, Chileshe N. Critical evaluation of off-site construction research: A Scientometric analysis. Automat Constr. 2018;87: 235-47.

[29] Aghaei Chadegani, A., et al., A comparison between two main academic literature collections: Web of science and scopus databases. Asian Social Science, 2013. 9(5): p. 18-26.

[30] He Q, Wang G, Luo L, Shi Q, Xie J, Meng X. Mapping the managerial areas of Building Information Modeling (BIM) using scientometric analysis. International Journal of 
Project Management. 2017;35(4): 670-85.

[31] Oraee M, Hosseini MR, Papadonikolaki E, Palliyaguru R, Arashpour M. Collaboration in BIM-based construction networks: A bibliometric-qualitative literature review. International Journal of Project Management. 2017;35(7): 1288-301.

[32] Butler, L. and M.S. Visser, Extending citation analysis to non-source items. Scientometrics, 2006. 66(2): p. 327-343.

[33] Tijssen, R.J.W. and A.F.J. Van Raan, Mapping Changes in Science and Technology: Bibliometric Co-Occurrence Analysis of the R\&amp;D Literature. Evaluation Review, 1994. 18(1): p. 98-115.

[34] Cobo MJ, López-Herrera AG, Herrera-Viedma E, Herrera F. An approach for detecting, quantifying, and visualizing the evolution of a research field: A practical application to the Fuzzy Sets Theory field. J Informetr. 2011;5(1): 146-66.

[35] Small, H., Visualizing science by citation mapping. Journal of the American Society for Information Science, 1999. 50(9): p. 799-813.

[36] van Eck, N.J. and L. Waltman, Software survey: VOSviewer, a computer program for bibliometric mapping. Scientometrics, 2010. 84(2): p. 523-538.

[37] Park JY, Nagy Z. Comprehensive analysis of the relationship between thermal comfort and building control research - A data-driven literature review. Renewable and Sustainable Energy Reviews. 2018;82: 2664-79.

[38] Su H, Lee P. Mapping knowledge structure by keyword co-occurrence: a first look at journal papers in Technology Foresight. Scientometrics. 2010;85(1): 65-79.

[39] Li, W., et al., Effects of graphene oxide on early-age hydration and electrical resistivity of Portland cement paste. Constr Build Mater, 2017. 136: p. 506-514.

[40] Li, W., et al., Effects of nanoalumina and graphene oxide on early-age hydration and mechanical properties of cement paste. Journal of Materials in Civil Engineering, 2017. 29(9).

[41] Lv, S., et al., Regulation of go on cement hydration crystals and its toughening effect. Magazine of Concrete Research, 2013. 65(20): p. 1246-1254.

[42] Lu Z, Hou D, Ma H, Fan T, Li Z. Effects of graphene oxide on the properties and microstructures of the magnesium potassium phosphate cement paste. Constr Build Mater. 2016;119: 107-12.

[43] Li H, Du T, Xiao H, Zhang Q. Crystallization of calcium silicate hydrates on the surface of nanomaterials. J Am Ceram Soc. 2017;100(7): 3227-38.

[44] Lv S, Zhang J, Zhu L, Jia C. Preparation of Cement Composites with Ordered Microstructures via Doping with Graphene Oxide Nanosheets and an Investigation of Their Strength and Durability. Materials. 2016;9(12): 924.

[45] Lv S, Hu H, Zhang J, Luo X, Lei Y, Sun L. Fabrication of GO/Cement Composites by Incorporation of Few-Layered GO Nanosheets and Characterization of Their Crystal/Chemical Structure and Properties. Nanomaterials-Basel. 2017;7(12): 457.

[46] Zhou C, Li F, Hu J, Ren M, Wei J, Yu Q. Enhanced mechanical properties of cement paste by hybrid graphene oxide/carbon nanotubes. Constr Build Mater. 2017;134: 33645.

[47] Zeyu Lu ADHB. Mechanism of cement paste reinforced by graphene oxide/carbon nanotubes composites with enhanced mechanical properties. Rsc Adv. 2015: 100598605.

[48] Chuah S, Pan Z, Sanjayan JG, Wang CM, Duan WH. Nano reinforced cement and concrete composites and new perspective from graphene oxide. Constr Build Mater. 2014;73: 113-24.

[49] Zhao L, Guo X, Ge C, Li Q, Guo L, Shu X, et al. Mechanical behavior and toughening 
mechanism of polycarboxylate superplasticizer modified graphene oxide reinforced cement composites. Composites Part B: Engineering. 2017;113: 308-16.

[50] Al-Saadi NTK, Mohammed A, Al-Mahaidi R. Fatigue performance of near-surface mounted CFRP strips embedded in concrete girders using cementitious adhesive made with graphene oxide. Constr Build Mater. 2017;148: 632-47.

[51] Al-Saadi NTK, Mohammed A, Al-Mahaidi R. Fatigue performance of NSM CFRP strips embedded in concrete using innovative high-strength self-compacting cementitious adhesive (IHSSC-CA) made with graphene oxide. Compos Struct. 2017;163: 44-62.

[52] Mohammed A, Al-Saadi NTK, Al-Mahaidi R. Assessment of bond strength of NSM CFRP strips embedded in concrete using cementitious adhesive made with graphene oxide. Constr Build Mater. 2017;154: 504-13.

[53] Al-Saadi NTK, Mohammed A, Al-Mahaidi R. Assessment of residual strength of concrete girders rehabilitated using NSM CFRP with cementitious adhesive made with graphene oxide after exposure to fatigue loading. Constr Build Mater. 2017;153: 402-22.

[54] Lu Z, Hanif A, Ning C, Shao H, Yin R, Li Z. Steric stabilization of graphene oxide in alkaline cementitious solutions: Mechanical enhancement of cement composite. Mater Design. 2017;127: 154-61.

[55] Lu Z, Li X, Hanif A, Chen B, Parthasarathy P, Yu J, et al. Early-age interaction mechanism between the graphene oxide and cement hydrates. Constr Build Mater. 2017;152: 232-9.

[56] Li X, Lu Z, Chuah S, Li W, Liu Y, Duan WH, et al. Effects of graphene oxide aggregates on hydration degree, sorptivity, and tensile splitting strength of cement paste. Composites Part A: Applied Science and Manufacturing. 2017;100: 1-8.

[57] Lv S, Zhang J, Zhu L, Jia C, Luo X. Preparation of Regular Cement Hydration Crystals and Ordered Microstructures by Doping GON and an Investigation into Its Compressive and Flexural Strengths. Crystals. 2017;7(12): 165.

[58] Lv, S., et al., Effect of polyacrylate/GO nanocomposites on properties of cement paste. Magazine of Concrete Research, 2015. 68(4): p. 187-196.

[59] Lv S, Ma Y, Qiu C, Sun T, Liu J, Zhou Q. Effect of graphene oxide nanosheets of microstructure and mechanical properties of cement composites. Constr Build Mater. 2013;49: 121-7.

[60] Shang Y, Zhang D, Yang C, Liu Y, Liu Y. Effect of graphene oxide on the rheological properties of cement pastes. Constr Build Mater. 2015;96: 20-8.

[61] Horszczaruk E, Mijowska E, Kalenczuk RJ, Aleksandrzak M, Mijowska S. Nanocomposite of cement/graphene oxide - Impact on hydration kinetics and Young' s modulus. Constr Build Mater. 2015;78: 234-42.

[62] Pan Z, He L, Qiu L, Korayem AH, Li G, Zhu JW, et al. Mechanical properties and microstructure of a graphene oxide - cement composite. Cement and Concrete Composites. 2015;58: 140-7.

[63] Sharma, S. and N.C. Kothiyal, Influence of graphene oxide as dispersed phase in cement mortar matrix in defining the crystal patterns of cement hydrates and its effect on mechanical, microstructural and crystallization properties. RSC Advances, 2015. 5(65): p. 52642-52657.

[64] Singh AP, Mishra M, Chandra A, Dhawan SK. Graphene oxide/ferrofluid/cement composites for electromagnetic interference shielding application. Nanotechnology. 2011;22(46): 465701.

[65] Lu L, Ouyang D. Properties of Cement Mortar and Ultra-High Strength Concrete Incorporating Graphene Oxide Nanosheets. Nanomaterials-Basel. 2017;7(12): 187. 
[66] Mokhtar MM, Abo-El-Enein SA, Hassaan MY, Morsy MS, Khalil MH. Mechanical performance, pore structure and micro-structural characteristics of graphene oxide nano platelets reinforced cement. Constr Build Mater. 2017;138: 333-9.

[67] Li X, Wei W, Qin H, Hang Hu Y. Co-effects of graphene oxide sheets and single wall carbon nanotubes on mechanical properties of cement. J Phys Chem Solids. 2015;85: 39-43.

[68] Wang M, Yao H, Wang R, Zheng S. Chemically functionalized graphene oxide as the additive for cement - matrix composite with enhanced fluidity and toughness. Constr Build Mater. 2017;150: 150-6.

[69] Wang, Q., et al., Influence of graphene oxide additions on the microstructure and mechanical strength of cement. Xinxing Tan Cailiao/New Carbon Materials, 2015. 30(4): p. 349-356.

[70] Li X, Lu Z, Chuah S, Li W, Liu Y, Duan WH, et al. Effects of graphene oxide aggregates on hydration degree, sorptivity, and tensile splitting strength of cement paste. Composites Part A: Applied Science and Manufacturing. 2017;100: 1-8.

[71] Zhu XH, Kang XJ, Yang K, Yang CH. Effect of graphene oxide on the mechanical properties and the formation of layered double hydroxides (LDHs) in alkali-activated slag cement. Constr Build Mater. 2017;132: 290-5.

[72] Chuah S, Li W, Chen SJ, Sanjayan JG, Duan WH. Investigation on dispersion of graphene oxide in cement composite using different surfactant treatments. Constr Build Mater. 2018;161: 519-27.

[73] Qiu L, Yang X, Gou X, Yang W, Ma Z, Wallace GG, et al. Dispersing Carbon Nanotubes with Graphene Oxide in Water and Synergistic Effects between Graphene Derivatives. Chemistry - A European Journal. 2010;16(35): 10653-8.

[74] Mohammed A, Sanjayan JG, Nazari A, Bagheri A, Al-Saadi NTK. Inhibition of carbonation attack in cement-based matrix due to adding graphene oxide. Australian Journal of Civil Engineering. 2017;15(1): 20-31.

[75] Wang Q, Cui X, Wang J, Li S, Lv C, Dong Y. Effect of fly ash on rheological properties of graphene oxide cement paste. Constr Build Mater. 2017;138: 35-44.

[76] Properties. HDGO. Self-assembly and morphological control of three-dimensional macroporous architectures built of two-dimensional materials. Nano Today. 2017: 10023.

[77] Jiang RS, Wang BM. Mechanical Properties and Microstructure of Graphene-Cement Composites. Key Engineering Materials. 2017;748: 295-300.

[78] Cui H, Yan X, Tang L, Xing F. Possible pitfall in sample preparation for SEM analysis A discussion of the paper "Fabrication of polycarboxylate/graphene oxide nanosheet composites by copolymerization for reinforcing and toughening cement composites" by Lv et al. Cement and Concrete Composites. 2017;77: 81-5.

[79] Hou D, Lu Z, Li X, Ma H, Li Z. Reactive molecular dynamics and experimental study of graphene-cement composites: Structure, dynamics and reinforcement mechanisms. Carbon. 2017;115: 188-208.

[80] Fan D, Lue L, Yang S. Molecular dynamics study of interfacial stress transfer in graphene-oxide cementitious composites. Comp Mater Sci. 2017;139: 56-64.

[81] Gong, K., et al., Reinforcing effects of graphene oxide on portland cement paste. Journal of Materials in Civil Engineering, 2015. 27(2).

[82] Wang S, Zhang S, Wang Y, Sun X, Sun K. Reduced graphene oxide/carbon nanotubes reinforced calcium phosphate cement. Ceram Int. 2017;43(16): 13083-8.

[83] Kang D, Seo KS, Lee H, Chung W. Experimental study on mechanical strength of GO- 
cement composites. Constr Build Mater. 2017;131: 303-8.

[84] Qin H, Wei W, Hang Hu Y. Synergistic effect of graphene-oxide-doping and microwave-curing on mechanical strength of cement. J Phys Chem Solids. 2017;103: 67-72.

[85] Gholampour A, Valizadeh Kiamahalleh M, Tran DNH, Ozbakkaloglu T, Losic D. From Graphene Oxide to Reduced Graphene Oxide: Impact on the Physiochemical and Mechanical Properties of Graphene - Cement Composites. ACS Appl Mater Inter. 2017;9(49): 43275-86.

[86] Mohammed A, Sanjayan JG, Nazari A, Al-Saadi NTK. Effects of graphene oxide in enhancing the performance of concrete exposed to high-temperature. Australian Journal of Civil Engineering. 2017;15(1): 61-71.

[87] Tong T, Fan Z, Liu Q, Wang S, Tan S, Yu Q. Investigation of the effects of graphene and graphene oxide nanoplatelets on the micro- and macro-properties of cementitious materials. CONSTR BUILD MATER. 2016;106: 102-14.

[88] Properties. HDGO. Self-assembly and morphological control of three-dimensional macroporous architectures built of two-dimensional materials. Nano Today. 2017: 10023. 